\title{
Research on the impact of farmers' credit default risk -- from the perspective of social capital
}

\author{
Yanan Liu Jing Wang \\ College of Economics and Management, Northwest Agriculture \& Forestry University \\ Shanxi, China \\ 270454383@qq.com \\ 农户信贷违约风险的影响研究 \\ 一一基于社会资本视角 \\ 刘亚楠 王静 \\ 西北农林科技大学经济管理学院 \\ 陕西 712100 , 中国 \\ 270454383@qq.com
}

\begin{abstract}
Based on the survey data of farmers in shaanxi province in 2019, this paper attempts to identify the influencing factors of farmers' credit default risk from two aspects: farmers' willingness to repay loans and their ability to repay loans. This paper selects five indicators, including the farmer householder individual characteristics, family characteristics, family economic characteristics, geographic location and social capital, through Biprobit model analyzes the factors influencing the supply and demand of farmers' credit, through the Probit model, from two aspects of farmers' ability to repay the loan and their willingness to repay the loan ,to identify the factors that affect farmer credit default risk. The results show that social capital has a positive impact on farmers' ability and willingness to repay loans, and can reduce the risk of farmers' credit default. Therefore, farmer's social capital can be used as an effective reference index to predict farmer's credit default risk.
\end{abstract}

Keywords-credit default, repayment willingness, repayment ability, social capital

摘要一本文利用 2019 年对陕西省农户的调研数据, 试图从 农户偿贷意愿和农户偿贷能力两个方面识别农户信贷违约风险 的影响因素。本文选用农户户主个体特征、家庭基本特征、家 庭经济特征、地理位置和农户社会资本五个指标, 通过 Biprobit 模型分析了影响农户信贷的供需因素, 通过 Probit 模型, 从农户偿贷能力和偿贷意愿两个方面, 识别影响农户信 贷违约风险的因素。结果表明, 社会资本对农户的偿贷能力和 偿贷意愿均有正向影响, 能够降低农户信贷违约风险。因此, 农户社会资本可以作为预期农户信贷违约风险的有效参考指 标。

关键词一信贷违约，偿贷意愿，偿贷能力，社会资本

\section{I. 引言}

“三农” 问题一直以来都是关系我国国计民生的头 等大事。2018 年 1 月 2 日, 中央发布一号文件《中共中
央 国务院关于实施乡村振兴战略的意见》, 这是我国连 续 15 年将农业发展作为中央一号文件的主题。2014 年, 国家首次将农地承包经营权列为农户向金融机构融资的 抵押品, 以缓解农户信贷抵押不足，为了提供一个良好 的农村金融环境, 国家先后出台了一系列政策措施, 但 农户贷款难问题仍未从根本上得到解决，我国农村地区 金融抑制问题仍然严峻，农户有效抵押品仍然不足，农 村金融改革步伐与城乡一体化进程出现明显不协调。

据统计，我国农户中可以从正规渠道获得贷款的只 有 $27 \%$ ，民间金融机构获得贷款占 $33 \%$ ，另外的 $40 \%$ 则 是无法从金融机构获得资金支持。2017 年，我国银行业 金融机构涉农贷款投放实现了持续增长。但截至 2017 年 12 月末，全国涉农贷款余额 30.95 万亿元，只占整个银 行业金融机构贷款总额的四分之一，且村镇银行在农村 的覆盖比例较低, 在我国农村许多地区, 仍然缺乏信贷 服务的支持。

国内外学者研究发现在抵押物相对缺乏的地区和农 户抵押物变现相对困难的地区，社会资本可以充当抵押 物有效降低信用贷款的违约风险，而我国作为一个典型 的重视 “关系” 的国家, 在我国现阶段农村信贷市场存 在诸多问题, 农户抵押不足的情况下, 能否以社会资本 作为衡量农户还贷意愿和还贷能力的指标, 探讨社会资 本对农户信贷违约风险影响的作用机理, 具有重要的探 究意义。

\section{II. 农户信贷约束问题}

在完全信息的金融市场条件下，金融机构能够准确 观察借款人的行为, 虽然不能够直接控制借款人的还款 意愿，但可以利用信贷合同约束借款人的违约动机

（Stiglitz, et al.1981）。但农村信贷市场具有明显的信息 不对称性（王冀宁等，2007），信息篎选和甄别成本较 
高, 同时还存在由于农户文化素质较低等因素导致的道 德风险, 使农户信贷违约问题变得十分复杂 (Petrick, 2004）。

从农村信贷市场来看, 农村的信贷市场存在严重信 息不对称问题。农村信贷市场的复杂性以及农户资产相 对不透明的现实状况，使得金融机构很难真正实现信贷 风险的有效甄别。即使能够顺利开展甄别活动, 也可能 会出现事先甄别与未来还款意愿不匹配, 无法对农户事 后行为进行有效约束，如果农户谎报资金用途，将用于 经营性生产的贷款用于消费性用途（婚丧嫁娶等），将 很难在短时间内产生再生回报, 导致信贷违约（王冀 宁，赵顺龙，2007；丁志国等，2014）。

农村信贷市场也存在农户歧视问题，农户本身经济 基础就比较薄弱, 收入单一且不确定性大（周韵 2009, 季峰 2017）, 农户所从事的主要生产活动具有显著的内 在风险 (气候变动、病虫害以及突发性支出等) , 明显 地提高了农户信贷违约的风险概率（Rosenzweig 等, 1993 ），不仅如此，农户对金融知识缺乏了解，缺乏获 取利率变化和财务政策等市场信息的主动性, 获取相关 信息的渠道不够畅通，信息闭塞，都导致其资金的获利 能力较低, 进而影响农户最后的还贷能力, 增大违约风 险（李娟 2007）。

正规金融机构为了控制信贷风险，信贷决策时往往 附加诸多限制条件, 要求贷款人尽可能地提供担保, 来 降低风险, 但农户符合法定要求的抵押物很有限, 农村 的住房一般难以在短时间内转变为有效抵押品, 当前农 村区域产权市场不活跃, 贷款人处置抵押物的成本也很 高, 因而大部分农户无法满足正规部门发放贷款的要 求, 被排除在正规金融市场外。在不确定性较严重的情 况下，金融机构通常通过提高利率来调整局部收益风险 比, 也拒绝了不能接受高利率的农户进入正轨信贷市场 （McKinnon,1973;Shaw,1973）。然而，提高利率本身也 会带来消极效应, 使本来能够足额准时偿还贷款的农户 减少，最终导致违约风险提高（Basu，1997）。

显然，对于中国农村信贷市场而言，利率手段和抵 押担保都难以切实解决农户违约问题，一方面源于国家 对利率调整幅度的限制和对农村信贷的政策指导，另一 方面在于中国法律制度约束下农户所拥有的主要资产, 仍然面临不易变现和交易市场不健全的问题。基于此, 在 Grameen 银行推行的合作信贷成功之后, 人们认为社 会约束和群体监督维系的合伙体系能够降低农户违约的 倾向（Bhatt，1988; Huppi等，1990）。

\section{III. 社会资本对农户借贷行为的影响}

\section{A. 社会资本能够有效弥补农户贷款抵押物不足的缺陷}

研究表明基于地缘关系邻里之间建立的社会资本, 能够形成具有类似于抵押品的性质, 从而能够扩大农户 的资金渠道。社会资本在金融风险管理中具有 “抵押品 化的社会关系” 功能 (Biggart 和 Castanias, 2001) , 社 会资本在此起到经济担保的功能, 促使金融机构增加对 农户信用贷款而减少抵押贷款和质押贷款。严武等

（2014）认为农户借贷行为离不开社会资本，社会资本 在农户借贷行为中起到了重要的抵押和担保角色。胡枫 等（2012）研究发现: 社会网络对农户获得借贷的可得性
和借贷金额均具有显著的正向影响，与非正规金融借贷 相比，社会网络对正规金融机构借贷行为的影响更大。 国外学者 (Karlan 2007; Dinh Q H et al. 2012; Shoji M et al. 2012 ) 也得出一致结论认为社会资本在农户小额信贷 市场上弥补农户贷款抵押物不足起到了积极的作用。

\section{$B$. 社会资本有利于信息的传递, 缓解信息不对称问题}

Cornell 和 Welch（1996）认为社会资本有助于信贷 市场借贷双方进行篮选。同时, 社会资本可以缓解信贷 市场中信息不完备和不对称问题, 降低搜索成本、监督 和履约成本，从而节约小额金融交易成本（Kraton, 1996; Okten\&Osoli, 2004）。

\section{C. 社会资本可以约束农户的信贷违约行为, 降低农户信 贷违约风险}

由于极高的文化的同质性，同一社区的村民相互之 间不仅对彼此行为方式非常了解, 情感与交流也容易沟 通。从关系的动态视角看, 这种内部互惠关系有助于形 成良好的社会文化氛围, 强化农户彼此之间的信任和合 作, 对道德和信贷风险的化解也是个有力支撑, 降低了 整个区域农户信贷违约的风险性（刘一伟等 2018）。社 会资本通过违约者及其欺骗行为信息的快速传播和基于 网络的社会惩罚与社会压力增加借款人违约成本等方 式, 来减少违约行为的发生概率和降低信用风险。社会 资本在某种程度上可以替代司法机制促进金融合约履 行。张晓月和陈静 (2007) 认为, 社会资本参与信贷风 险控制的作用机理就是使金融机构更易收集相关信息, 通过组织内部的制度压力和社会压力来提高借款人还款 概率, 尤其是在中国农村信贷市场更需要借助于社会资 本降低监督和交易成本。刘成玉等（2011）指出农村社 会资本同样具有经济价值, 完全可以参与农村信贷风险 控制, 尤其是在充当抵押物方面。Alesinaetal (2013) 通 过实证得出结论, 银行贷款可得性与社会资本及信任水 平成正比。李庆海等 (2018) 通过将社会资本划分为正 式和非正式两类, 研究得出正式社会资本对农户信贷违 约具有显著的抑制作用。李庆海、孙光林等 (2018) 从 社会网络的角度研究得出, 不同类型的社会网络对农户 信贷违约风险的影响也不同，其中拥有较多团体性社会 网络的农户具有更强的还款能力和还款意愿。

\section{IV. 变量及模型选择}

\section{A. 因变量}

本文对农户信贷违约风险的衡量从农户的偿贷能力 和偿贷意愿两方面考虑。从理论层面上看, 行动意愿和 行动能力共同决定了行为结果, 具有较强偿贷能力但不 具备偿贷意愿会产生主动违约, 具有较强偿贷意愿但不 具备偿贷能力会造成农户被动违约。从金融机构实践中 的评估指标体系来看, 对农户预期是否会违约也是从偿 贷意愿和偿贷能力两个方面来考察的。

本文在借鉴相关文献的测度方法和农户实际情况的 基础上, 选取两个指标衡量农户偿贷能力, 两个指标衡 量农户偿贷意愿。

对农户偿贷能力, 本文通过偿贷能力 $1 、 2$ 两个指标 衡量, 还贷能力 1 :您家在全村是比较富裕的家庭么? 设 置非常不同意, 不同意, 一般, 比较同意和非常同意五 
个选项, 回答后三项的农户偿贷能力较强, 回答前两项 的农户偿贷能力较弱, 据此构建农户还贷能力是否较强 的二值虚拟变量, 偿贷能力较强取值为 1 , 否则取值为 0 。偿贷能力 2 :通过其 2018 年家庭基本生活总支出和家 庭总收入, 计算得出样本数据家庭基本支出占家庭总收 入的比重, 进而找出总体样本数据的中位数, 如果农户 比重大于中位数则认为其还贷能力较弱, 取值为 0 , 否 则认为其还贷能力较强, 取值为 1 , 从而构建农户还贷 能力是否较强的二值虚拟变量。农户家庭基本生活支 出, 采用询问农户过去一年每月平均基本支出的金额 （即每月用来购买基本生活必需品的金额），算出样本 农户一年家庭基本生活支出, 通过样本数量的收入支出 比, 来衡量农户在除去维持家庭基本支出后农户可支配 资金的比例，可支配的资金比例越大则还贷能力越强。

对农户偿贷意愿的衡量，本文采用了两个指标，偿 贷意愿 1 ：假如您有一笔银行或者信用社贷款, 还款时 您的收入远远低于您期望的水平而不足以归还时, 您会 节约您的日常开支来还钱么？偿贷意愿 2 ：假如您有一 笔银行或者信用社贷款, 还款时您的收入远远低于您期 望的水平而不足以归还时, 您会通过像他人借款来还钱 么? 对以上两个问题, 回答会的农户偿贷意愿较强（取 值为 1 ），回答不会的农户偿贷意愿较弱（取值为 0 ）。

\section{B. 核心变量}

借鉴相关学者对农户社会资本类型和维度划分，本 文测度与农户偿贷行为有关的社会资本两个维度：社会 网络和社会信任。社会网络通过经常往来的人数和过年 过节用于人情往来的支出进行测度; 社会信任通过农户 对网络成员的信任程度、在做重大决定时是否会询问意 见、拜访的频率以及在遇到困难时网络成员能否提供帮 助。除去社会网络中的两个变量用实际数值度量外, 其 他变量根据农户对频率、评价与感受的回答, 采用五级 评分标准为调查对象打分。

将社会资本样本数据计算得到 $\mathrm{KMO}$ 检验值为 0.697 , Bartlett 球形检验近似卡方值为 312.799 （ $\mathrm{sig}=0.000 ）$ ，表明样本数据适合做因子分析，本文采 用最大方差法进行因子旋转, 采用提取主成分法提取特 征根大于 1 的两个公因子, 累计贡献率为 $67.579 \%$, 公 因子 1 的贡献率为 $35.159 \%$, 公因子 2 的贡献率为 $67.579 \%$; 分别用各公因子的方差贡献率为权重, 对社会 资本的两个维度因子得分加总求和, 计算得出每个样本 的社会资本指数。

\section{C. 控制变量}

本文从农户户主个体特征（农户年龄、受教育程 度、健康状况）和家庭基本特征（家庭人口数、是否有 人外出务工）、家庭经济特征（家庭固定资产状况、家 庭平均每月基本生活费用、2018 年家庭总收入、是否办 理保险、2018 家庭种植耕地数量) 和地理位置（离银行 距离）四个方面设置了控制变量。

\section{D. 模型选择}

本文首先利用 Biprobit 模型分析农户基本特征对农户 信贷需求与信贷可得性的影响, 然后进一步利用 Probit 模型探究农户社会资本对农户偿贷能力和偿贷意愿的影 响。
由于农户信贷需求和金融机构信贷供给为二元离散 变量, 且信贷需求和信贷供给之间具有内在关联性, 因 此我们采用 Biprobit 模型。模型设定形式如下: 用 $Y_{1}$ 和 $Y_{2}$ 分别表示金融机构是否愿意向农户提供贷款和农户是 否有向金融机构借款的需求。 $Y_{1=1}$ 表示金融机构愿意提 供贷款, 而 $Y_{1=0}$ 表示其不愿意提供贷款; $Y_{2}=1$ 表示农 户有借款需求, 而 $Y_{2}=0$ 表示其没有贷款需求, 用 $Y_{1}^{*}$ 和 $Y_{2}^{*}$ 分别表示金融机构提供贷款和农户有借款需求的潜在 变量, 且为不可观察的两个变量。

$$
\left\{\begin{array}{l}
Y_{1}^{*}=\beta_{1} X_{1}+\varepsilon_{1} \\
Y_{2}^{*}=\beta_{2} X_{2}+\varepsilon_{2}
\end{array}\right.
$$

$X_{1}$ 是表示影响金融机构信贷供给抉择的影响因素, $X_{2}$ 是表示影响农户信贷需求的影响因素, $\beta_{1}$ 和 $\beta_{2}$ 是待 估计系数, 扰动项 $\left(\varepsilon_{1}, \varepsilon_{2}\right)$ 服从二维联合正态分布, 期望 为 0 , 方差为 1 , 相关系数为 $\rho$, 潜在变量 $Y_{1}^{*}$ 和 $Y_{2}^{*}$ 与虚 拟变量 $Y_{1 \text { 和 }} Y_{2}$ 的关系如下:

$$
Y_{1}=\left\{\begin{array}{l}
1, Y_{1}^{*}>0 \\
0, Y_{1}^{*} \leq 0
\end{array}, Y_{2}=\left\{\begin{array}{l}
1, Y_{2}^{*}>0 \\
0, Y_{2}^{*} \leq 0
\end{array}\right.\right.
$$

同时，用 $\mathrm{Y}$ 表示农户是否发生了借款行为，若 $\mathrm{Y}=1$ 表示农户发生了借款行为, 得到了贷款; 若 $Y=0$ 表示农 户没有发生借款行为。 $\mathrm{Y}$ 与 $Y_{1} 、 Y_{2}$ 关系如下:

$$
Y=\left\{\begin{array}{l}
1, Y_{1}=1 \text { 且 } Y_{2}=1 \\
0, Y_{1}=0 \text { 且 } Y_{2}=0
\end{array}\right.
$$

因为存在信息不完全, 无法识别信贷供给和需求的 具体情况, 只能观测到农户最终信贷行为的具体情况, 即可以获得 $\mathrm{Y}=1$ 和 $\mathrm{Y}=0$ 的具体值, 而无法获得 $Y_{1}$ 和 $Y_{2}$ 的全部具体值。因此, 采用 Biprobit 模型及其估计方 法。

根据对农户是否有偿贷能力以及是否有偿贷意愿, 设置 “是 $=1$, 否 $=0$ ” ，对偿贷能力 1 、偿贷能力 2 、偿贷 意愿 1 和偿贷意愿 2 本文都选择建立二元 Probit 模型来 分析。

$$
\begin{aligned}
& P(Y=1 \mid X)=P\left(Y^{*}>0\right)=P\left(\mu>-\left(\beta_{0}+\beta X\right)\right) \\
& =1-\left(\phi-\left(\beta_{0}+\beta X\right)\right)=\phi\left(\beta_{0}+\beta X\right)
\end{aligned}
$$

其中, $P$ 表示概率, $\phi$ 为标准正态累计分布函数, 由 此建立 Probit 回归方程为 ( $\beta_{0}$ 为常数项, $\beta_{\mathrm{i}}$ 为解释变 量的回归系数, $\mu$ 为误差项）:

$$
Y^{*}=\beta_{0}+\beta_{1} X_{1}+\beta_{2} X_{2}+\ldots+\beta_{\mathrm{m}} X_{\mathrm{m}}+\mu
$$




\section{V. 结论与讨论}

使用 STATA12.0, 运用样本数据, 对 Biprobit 模型 进行估计, 结果见下表 1 。从整体看, 模型与数据拟合 较好。逆米尔斯比率 $($ athrho $=0.819)$ 的估计系数在 $5 \%$ 的水平上显著, 表明信贷需求方程显著影响信贷供给方 程, 且两个方程的相关系数 (rho) 为 0.674 , 说明二者 相关关系明显。可见金融机构向农户发放贷款的决策是 以农户的信贷需求基础。从信贷需求方来看, 农户的家 庭人口数, 户主年龄, 健康状况都对农户的信贷需求有 负向影响。可能的原因是, 大部分家庭规模较大的农 户，也会拥有较多的劳动力，农户借贷的可能性会降 低; 而户主年龄越大、健康程度越差对于信贷的需求就 越小, 可能的原因是, 随着农户年龄增大, 农户改变现 状的期望会降低, 而相对的生活成本和经济要求也比较 低; 而健康程度较差的农户, 预期自身还贷能力较低, 会降低其信贷需求。农户受教育程度和家庭总收入都对
源, 畅通的信息渠道而有更强获利能力, 从而提高其获 贷的可能性。

本文采用 probit 模型, 对影响农户信贷违约的四个指 标进行因素分析, 由表 2 可知, 农户社会资本的总存量 越大，农户偿贷能力和农户偿贷意愿越大。农户增加资 本的投入，表明其所拥有的社会资本可以提供其所希望 获得的资源或者信息渠道, 进而提高农户经济能力, 随 着农户对其社会资本的投入增加，其违约带来的成本变 大，农户的违约的可能性降低。

在对农户偿贷能力 1 的因素分析中，模型估计结果 较差, 可能的原因是偿贷能力 1 采用的指标是受主观态 度影响较大; 家庭总收入对农户偿贷能力 1 和偿贷能力 2 的影响均为正，这表明农户家庭总收入越多农户就越可 能具备偿贷能力; 农户家庭人口数, 家庭种植数量对农 户偿贷能力 2 的影响为负, 这可能是因为农户家庭人口

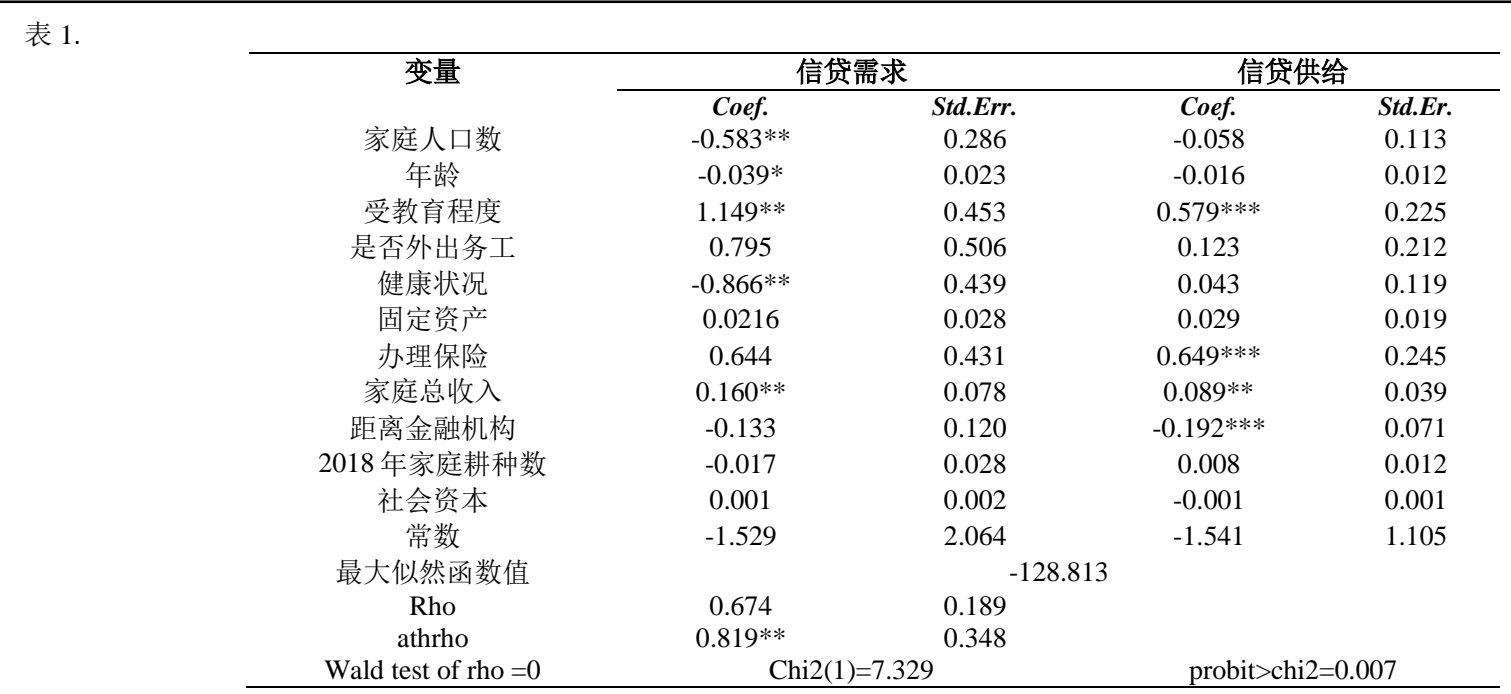

表 2.

\begin{tabular}{ccccc}
\hline 项目 & 偿贷能力 1 & 偿贷能力 2 & 偿贷意愿 $\mathbf{~}$ & 偿贷意愿 2 \\
\hline 家庭人口数 & -0.185 & $-0.316^{* * *}$ & -0.076 & 0.057 \\
年龄 & 0.019 & $0.027^{* *}$ & 0.006 & $-0.044^{* * *}$ \\
受教育程度 & 0.024 & -0.299 & -0.219 & -0.268 \\
是否外出务工 & 0.196 & -0.129 & 0.108 & 0.018 \\
健康状况 & -0.226 & 0.121 & -0.104 & $-0.291^{* *}$ \\
固定资产 & 0.009 & -0.021 & -0.020 & -0.009 \\
办理保险 & -0.055 & -0.060 & $0.655^{* *}$ & 0.389 \\
家庭总收入 & $0.269^{* * *}$ & $0.258^{* * *}$ & $-0.642^{*}$ & -0.042 \\
距离金融机构 & 0.012 & 0.045 & -0.103 & $-0.431^{* * *}$ \\
2018 年家庭耕种数 & -0.031 & $-0.052^{* * *}$ & $-0.038^{* *}$ & -0.001 \\
社会资本 & $0.003^{* * *}$ & $0.001^{* *}$ & $0.001^{* * *}$ & $0.002^{* * *}$ \\
常数 & -2.556 & -1.08 & 3.396 & 4.514 \\
\hline
\end{tabular}

*表示在 $10 \%$ 的统计水平上显著, **表示在 $5 \%$ 的水平上显著, $* * *$ 表示在 $1 \%$ 的统计水平上显著

农户信贷需求有正向影响。可能的原因是，受教育程度 较高的农户，其获取信息的能力和投资的意愿也相对较 强, 更希望通过信贷资金来提高生活状况; 家庭总收入 较高的农户可能会因为其拥有较强的经济基础和获益较 大的投资项目, 从而促使其信贷需求增大。从信贷供给 来看, 户主受教育程度, 家庭总收入和是否办理保险都 正向影响农户的获贷情况，表明目前影响金融机构放贷 的主要因素为农户收入和其收入的稳定; 受教育程度较 高的农户可能会因为拥有较高的社会地位, 丰富社会资
数较多, 可能意味着家庭中有需要教育支出的学生或需 要被照顾的老人, 教育支出和医疗支出相对较大, 可能 会增加农户的不确定性支出, 而农户家庭种植数量越 多, 会因为自然灾害等非人为因素的影响而增加其农业 收入的不稳定性, 反而负向影响家庭偿贷能力。

农户办理保险对其偿贷意愿 1 有正向影响, 说明保 险业务的办理可以对农户未来经济情况和生活状况起到 一定的稳定作用, 保障农户基本生活, 提高农户的偿贷 
意愿; 农户的种植数量对偿贷意愿 1 的影响为负, 说明 农户种植数量越多, 其农业收入的不稳定性会影响偿贷 意愿。结果表明, 家庭总收入对偿贷意愿的影响并不是 正向的, 表明依靠农户家庭总收入来预期农户未来违约 风险并不可靠的。

对农户偿贷意愿 2 的影响因素中，控制变量中户主 年龄, 健康状况及农户家庭住址离银行的距离对农户偿 贷意愿的影响均为负，可能的原因是年龄较大的农户对 其收入资金的不确定和收入来源的不稳定会降低他的偿 贷意愿, 也可能随着年龄的增长对违约带来的负面影响 的在意程度降低, 偿贷意愿整体下降; 农户的健康状况 越差, 会因为相应的医药费用增加而降低农户可支配收 入，降低农户对未来生活的预期状态，影响农户的偿贷 意愿, 而农户离银行越远获取银行政策信息的渠道就越 不畅通，影响其偿贷的意愿。

本文的研究发现，农户社会资本能够影响农户的偿 贷能力和偿贷意愿, 农户可以主动和有选择的投入社会 资本，进而发挥社会资本制度属性和资源属性的作用， 通过激励和约束两个方面提高农户偿贷意愿; 农户拥有 的社会资本又能够为他提供所需的资源和信息渠道，改 善农户的经济状况。基于此, 在我国农村信贷市场农户 基本信贷需求得不到满足的情况下，金融机构可以将社 会资本作为一个参考指标, 更好的找到有偿贷能力且偿 贷意愿较高的农户，精准放贷，满足农户信贷需求的同 时，保证银行的效益。

\section{致谢}

感谢西北农林科技大学经济管理学院王静教授的指导 和支持, 本研究由国家自然科学基金农户生产联结
（PPL）机制及其关联性信用风险演化机理研究资助 (71873101)。

$$
\text { 参考文献 }
$$

[1] Xin Song, Li Li, Lei Xiao. "Review of research on credit risk management for rural credit cooperatives," vol 7, issue1-4, pp.21-26., 2017

[2] Kaicheng Xing,Shujun Guo. "Study on Meteorological Service Policy for Agricultural Insurance in Hebei Province under the Background of Climate Change," vol.9, issue1, pp.36-42, 2019.

[3] 胡枫, 陈玉宇. “社会网络与农户借贷行为一来自中国家庭动态跟 踪调查(CFPS) 的证据”金融研究, vol. 12,pp. 178 -192, 2012.

[4] 苏治,胡迪. “农户信贷违约都是主动违约吗一非对称信息状态下的 农户信贷违约机理”管理世界, vol.9, 2014

[5] 季峰, “银行农户小额贷款风险防控研究,”现代金融 vol. 1, pp.49-50, 2017

[6] 李爱喜. “社会资本对农户信用行为影响的机理分析,”财经论从, vol .1, pp.49-55, 2014

[7] 李庆海, 吕小锋, 李成友, 何婧. “社会资本对农户信贷违约影响 的机制分析”农业技术经济,vol 2, pp.104-118, 2018.

[8] 李庆海, 吕小锋, 李锐, 孙光林. “社会资本有助于农户跨越融资 的双重门槛吗? - - 基于江苏和山东两省的实证分析” 经济评论,vol .6 pp.136-149, 2016.

[9] 严武,陈喜. “社会资本视角下农户借贷行为影响因素分析一基于江 西 1294 个调查样本的实证” 江西社会科学, vol 8, pp.210-215, 2014

[10] 刘一伟,フ力. “社会资本、非农就业与居民贫困,”华南农业大学学 报（社会科学版） vol 2, issue 17, 2018

[11] Stiglitz J.E.,A.Weiss. "Credit Rationing in Markets with Imperfect Information," The American Economic Review. vol 71, issue 3, pp.393-410, 1981.

[12] Karlan D S. "Social connections and Group Banking," The Economics journal, vol 17, pp, F52 - F84, 2017.

[13] Shoji M. Aoyagi K. Kasahara R. et al. "Social Capital Formation and Credit Access: Evidence from Sri Lanka." World Development, vol 40 issue 12 pp. $2522-2536,2012$.

[14] Dufhues,T., G.Buchenrieder,H.D.Quoc,N.Munkung,"Social Capital and Loan Repayment Performance in South Asia," The Journal of Socio-Economics, vol 40, issue 5 pp.679-69, 2011. 